in recent years on everything from renewable energy and neuroscience to an assortment of Google $\mathrm{X}$ pet projects and at least three efforts to fight cancer.

Perhaps the United States was due for another national promise to cure cancer: the last - a 2005 pledge by Andrew von Eschenbach, then head of the US National Cancer Institute - was scheduled to have vanquished the disease by 2015. This followed then President Richard Nixon's 1971 pledge to use $\$ 100$ million to cure cancer. To be sure, pledges to cure cancer have a long history of succeeding in one respect: fundraising. But the idea that $\$ 1$ billion could eliminate cancer is misleading, and only becomes more so as each passing year reveals more about the full challenge of fighting the disease. With apologies to Biden, the more we 'know it' the harder it becomes to think we can 'eliminate cancer'.

Today, we have a clearer view of cancer's complexity. The sequencing of tumour genomes has revealed heterogeneity not only among cancers and patients, but in a single tumour. Within those complex mixtures of cells can lurk mutations that give rise to drug resistance. Therapies against cancer-causing mutations have been transformative for some patients in the short term, but nearly always fail in the long term as resistant cells reseed the tumour.

Real progress is being made, little by little. Chemotherapy cures more than $85 \%$ of children with acute lymphocytic leukaemia, for example. And for a small number of patients with various cancers, new immunotherapies have produced remissions so prolonged that doctors have begun to whisper the word 'cure'. But although combinations of these therapies could hold the key to expanding their success, testing combinations in clinical trials is complex - and quite likely to cost more than $\$ 1$ billion. As with everything, the more successful we get, the harder it is to improve. For many cancers, a more reasonable aim might be to turn them into chronic, manageable diseases.

In statements and conversations, Biden has acknowledged this complexity, and has even reportedly expressed regret for choosing the moonshot theme. It is unfortunate that sound bites from Biden and

the White House continue to back its simplistic framework. Repeated invocations of these bold but doomed quests to cure cancer in a decade, or with a given sum of money, feed public cynicism about the value and potential of science. And setting an unreachable goal plays down the tremendous progress that cancer researchers have made.

Details of the latest cancer moonshot are sketchy; Biden is still gathering input from the country's scientific glitterati. From what we know, he

"Setting an goal plays down

the tremendous

progress

that cancer

researchers

have made." hopes to double the pace of cancer research by breaking down the barriers - logistical and cultural - that keep researchers from sharing data. This can include having electronic medical records that talk to one another, encouraging collaboration, and developing central repositories that can handle big data. Some of these issues are already being tackled: the National Cancer Institute, for example, is putting together a large database that aims to unite disparate data sets, along with clinical information and the privacy concerns entailed, in one place.

There is also no guarantee that Obama's $\$ 1$-billion request will come to pass. Congressional leaders have pledged to ignore the president's budget request. And Obama sought to establish the funding for the cancer moonshot using an unusual approach that would circumvent the usual congressional funding process. Congress is unlikely to sign up to that. But there is hope that the programme will survive in some form: this Congress has a soft spot for medical research, and Biden is an authority on the art of congressional compromise.

Let us hope it will. Biden's early vision of the programme, if executed well, has the potential to be high-impact. Cancer research is in the middle of a revolution, and may be on the brink of even greater success. The US Cancer Moonshot has the potential to build on this momentum. The project does not need to mislead the public, and damage its trust in science, in the process.

\section{Chow down}

\section{Scientists should pay more heed to the varying effects of diet and environment on animal work.}

$\mathrm{J}$ apanese scientists last year reported the results of an extraordinary experiment in animal nutrition. The mice they worked with could well have been the best fed in the history of research - not in terms of quantity of food, but in its quality.

On a typical day, one group of mice got to eat mixed rice with dried whitebait and green seaweed flakes for breakfast, together with cooked beans and miso soup containing the root vegetable taro and Japanese mustard spinach. Another group got bacon and eggs, toast and fluffy boiled potatoes. Lunch for one group could be simmered pumpkin and ground chicken, with a portion of cucumber and wakame seaweed with vinegar dressing. A different group of mice got a hamburger and salad.

Dinner was selected by the scientists from dishes including prawns with chilli sauce, Sichuan-style bean curd, fried Japanese horse mackerel, white radish and shimeji mushroom soup, sake-steamed clams and steamed Japanese seerfish. The mice ate from that kind of menu every week of their lives. There was no pudding, but probably no complaints.

The reason for all this gourmet cuisine was to recreate the typical Japanese diet from decades past, and to examine its impact on health. The long life expectancy of people in Japan has been attributed to the benefits of Nihon shoku or traditional diet, involving fermented foods that seem to boost the protective effect of harmless microbes on and in the body. As the food available in Japan has become increasingly Westernized, the effects on health are being questioned.
Hence the mouse study. Each group was given dishes from recreated daily menus for a typical Japanese household in 1960, 1975, 1990 and 2005. The food was ground up and fed to the animals along with their regular meals of 'standard laboratory chow'. As the scientists suspected, the animals that were fed the older, more traditional diets lived and prospered for longest (K. Yamamoto et al. Nutrition 32, 122-128; 2016).

There are two things to note. The first is the large contribution that the environment - in this case diet - can make to health. The second is that such experiments enable the impact of environment on health to be assessed in ways that are simply not possible for human trials.

Light, heat, food, company, exercise, distractions, stress - all are at the fingertips of scientists who set up mouse experiments. Subtle changes in any of these can lead to profound, and potentially useful, discoveries about how health is changed by external factors. Research has probed, for example, how giving mice tunnels, stairs and wheels to play with can alter how female mice interact with their young, which in turn alters the brain development of the offspring (T. Begenisic et al Neurobiol. Dis. 82, 409-419; 2015). There is some evidence that modern, sterile, individually ventilated cages - used to minimize the effects of environmental factors such as disease - are quieter and less smelly for the mice, which reduces stimulation of those sensory systems.

Given that we know that environment affects the outcome of experiments, it is surprising that we don't know more about the environmental set-up of other studies - those that test the impact of a potential medical treatment, for example. As we report in a News story on page 264, many researchers who use mice do not even know
D NATURE.COM To comment online, click on Editorials at: go.nature.com/xhunqv the content of standard lab chow and how it may change from study to study. As scientists hunt for sources of irreproducibility in their research, variation in living conditions - and how to reduce it - deserves more attention. 